value to record an experiment, which is unique, or difficult to repeat. A recent example of such use was the film "The Release of Cosmic Ray Balloons", made and introduced by J. H. Davies, of the H. H. Wills Physical Laboratory, University of Bristol. Balloon launchings extending over several years in Great Britain and abroad were filmed, and by careful analysis of these records it was possible to improve the technique considerably. The initial acceleration of the rising bailoon could be reduced considerably by the use of a winch instead of employing many open-ended sandbags. Similarly, an undesirable mushrooming effect, leading to very high stresses in the envelope, could be eliminated by using a cord of undrawn nylon which stretched to several times its original length and thus allowed a gentle lifting of the heavy load.

High-speed cinematography was employed in three research films presented to the meeting. Wing Commander F. Latham, of the R.A.F. Institute of Aviation Medicine, Farnborough, began with unassisted escape from aircraft, showing the limitation of whole-body movements under sustained acceleration by comparing dummy and live-body trajectories on meeting high-speed slip streams at the commencement of free fall from aircraft exits. Camera frequencies up to $200 \mathrm{ft}$./sec. were used. The second stage, namely, of assisted escape from aircraft in the form of seat ejection, was similarly filmed and allowed a detailed physiological investigation of the tolerance of the human body to vertical impact acceleration and high-speed wind blasts. "Experiments of Sideways Launching" of ships was the next film to employ high-speed cinematography. It was extremely well recorded by C. A. Guthrie, of the Central Photographic Section of the National Physical Laboratory, often under most trying conditions. Scientific direction of this work was the responsibility of $\mathrm{D}$. J. Doust, and the film was introduced by R. Silverleaf, both of the Ship Division of the National Physical Laboratory. The main problems concerned the possibility of capsizing due to insufficient stability, structural damage, and hull pressure due to impact. Full-scale launchings were filmed, sometimes from several different camera positions at the same time, and similarly model experiments with $1 / 18$ scale models were recorded. From such experiments and these films, the performance of a variety of hull forms at launching can now be predicted and dangerous conditions of stability, way-end velocity and static drop can be avoided.

The only industrial research film presented at the meeting also employed high-speed cinematography, at a camera frequency of $1,000 \mathrm{ft}$. $/ \mathrm{sec}$. It was made in colour and introduced by J. Underwood, of the Guest, Keen and Nettlefolds Group Research Laboratory. It dealt with "Flame Movement in an Open Hearth Furnace during Tapping" and was taken to investigate the causes of local overheating ; from the resulting records it was possible to direct the research into profitable channels. During tapping the furnace is tilted, and from the research films made during this process, it became clear that the flame was not homogeneous, that patches of unburnt oil remained, and that the existence of turbulent edges showed undesirable changes of the aerodynamic conditions.

A number of comments may be submitted in this report. Out of the eleven presented, only one research film would find undisputed international acclaimthat introduced by Dr. Ambrose. Apparently only one research worker, Dr. Sainsbury, has used scientific cinematography in a metrical manner and has derived quantitative data from his research film; the majority of those presented could have been submitted to frame-analysis and would have yielded a mass of sčientific information, completely lost by mere projection and visual inspection of the film. In nearly all cases a professional photographer or cinematographer was employed in the production of each film; yet much could be said in detailed criticism. These comments are strong support for the creation of a central institute from which advice, comment and specialized equipment could be obtained.

However, the general picture is encouraging and in the years to come may lead to an improved position. There can be little doubt that the aims of the organizers of this meeting were fultilled by presenting a selection of the best research films available to an audience of scientists at the British Association. A third meeting is planned for September 7, 1957, at Dublin, and the hope can only be reiterated in this article that all those who have made new research films in the meantime will present their results ; the films should be submitted to either the Scientific and Technical Group of the Royal Photographic Society or to the Scientific Film Committee of the British Association.

A. R. Michaelis

\section{CLIMATOLOGY IN THE SERVICE OF MAN}

A

$T$ the Sheffield meeting of the British Association, Section E (Geography), under the presidency of Prof. A. Austin Miller, of the University of Reading, devoted a day to a series of contributions on "Climatology in the Service of Man", which might well be regarded as a very appropriate development following the presidential address (summarized in Nature, September 1, p. 474).

Prof. G. Manley opened by directing attention to the growing economic significance to Britain of the fact that we now import about 4 per cent of our fuel as coal or its equivalent. This is about equal to the difference in the requirement of fuel for heating purposes imposed by a severe season as compared with a mild one-the season comprising the months September-May. Variations in demand show an approximately linear relationship with the accumulated deficit of mean monthly temperature below a value which he took as $57^{\circ}$ at sea-level. Official statistics of annual means back to 1866 have already been used in studies of variations in fuel demand; but for England and Wales monthly means are only available from 1901. Prof. Manley stated that his purpose was to extend our knowledge of the vicissitudes; he showed that a table of monthly means (Quart. J. Roy. Met. Soc., 1953) giving representative values for the past 250 years now provides a reasonable index of the probable fluctuations of the heating requirement for the greater part of Britain. He directed attention to the occurrence in late Victorian times of the combination of a severe winter with $a_{*}$ protracted cold spring, which if repeated would set up demands in excess of any seasons so far experienced this century, in which $1916-17$ and $1950-51$ gave the highest values. The highly irregular incidence of severe seasons gives as yet little reason for supposing that a protracted cold season such as occurred in the 
1880's may not occur at any time. The need for further climatological research assumes greater urgency in view of our precarious fuel position.

Mr. M. Parry, of the University of Reading, followed with an appropriate reminder of the factors governing heat losses from a house. His remarks were based on studies made by the Building Research Station. Using the standard technique of degreedays, he then presented useful data from Reading, Bath and Nottingham to show the differences in fuel requirement likely to arise between houses of similar type, within and without the built-up area. Making further allowances for the wind factor, local variations of the order of 25-30 per cent in the annual fuel bill can be expected. Urban studies were rewarding.

Dr. Alice Garnett directed the attention of the audience to a variety of published studies in regard to atmospheric pollution, and went on to demonstrate the unpleasant--indeed disturbing and potentially lethal-accumulations which might be set up in certain parts of the Sheffield area, where a number of gauges have been established. Here she made effective use of maps indicating the association with local relief. She drew emphatic conclusions regarding the need for very close study of the problems which might arise from the siting of new 'industrial zones' in an area with such well-marked relief and a day-and-night outpouring of smoke.

Miss E. M. Frisby, who is working with a wellknown commercial advisory and consultant organization in the United States, summarized the way in which climatological information can be presented for the use of various clients engaged, for example, in building construction in remote country, or in the processing of food crops. The comment was made that in Britain such provision of information is a public service.

The afternoon papers were primarily concerned with evaporation. Mr. G. Melvin Howe (Aberystwyth) demonstrated maps of seasonal water surplus and deficit, based on the Thornthwaite formulæ, for England and Wales. Clarity in cartographical representation is a valuable service which the geographer can and does render ; a comment, however, might be that the representative character of the fundamental statistics used might be questioned in view of the local characteristics of stations to which Mr. Parry had earlier directed attention. Mr. S. Gregory (Liverpool) re-emphasized the need for water storage and conservation. In reminding the audience that since H. R. Mill geographers had taken little interest in rainfall, he summarized the type of work already done and stressed the need for further cartographical studies, especially in the north of England, where industrial demand for water is rising much more rapidly than was forecast.

Prof. B. J. Garnier, of Ibadan, brought in a welcome contribution from overseas. Irregular incidence of the short bursts of intense rainfall in Nigeria, coupled with very high evaporation, seldom much less than $4 \mathrm{~mm}$. daily, explain why a slight deficiency is quickly felt. He showed how in relatively well-watered country irrigation may nevertheless be very valuable, especially as the increase in the population will soon necessitate more intensive production of food.

Mr. J. L. N. Sibbons (Sheffield), at the end of the session, taxed the non-mathematical part of the audience; he gave a carefully reasoned demonstration of the difficulty of determining the potential loss of moisture under specified climatic conditions.
He showed that the assessment of evaporation-losses by the Thornthwaite method breaks down in certain unusual climates. From another point of view he showed that Penman's approach is also open to some criticism; and, taking account of Sir Graham Sutton's work, he proposed equations which would give better estimates. This was a bold and wellreasoned paper in an exacting field, and it is to be hoped that Mr. Sibbons's ideas will find outlet in print; at least one expert from the Meteorological Office was observed to be engaged in animated comment on the equations on the board.

The papers were varied, and served at least one useful purpose, in that they showed the value, as a shorthand summary of results and as a stimulus to discussion, of well-drawn maps and diagrams, although at times the observational basis may be open to question. Many in the audience were perforce little acquainted with the numerous specialized studies now forthcoming from various sources and research groups. The eritically minded geographer can render a useful service in assembling and filtering such material. The geographical approach, moreover, can be illuminating, in that the results of scientific investigations can be related to a particular area and tested by the members of the audience against their own direct field-experience and observation elsewhere.

\section{INTERNATIONAL UNION OF FOREST RESEARCH ORGANIZATIONS}

\section{CONGRESS IN OXFORD}

$7 \mathrm{HE}$ Twelfth Congress of the International Union of Forest Research Organizations was held in Oxford during July 7-14 under the presidency of Prof. Aldo Pavari, of Florence. At this, the first occasion on which the Union had held a Congress in Britain, about 250 delegates attended, from forty-two different countries. The Union, which was founded in 1890, is an association of forest research institutes, including universities, industrial research stations and State institutes, and its main purpose is to advance research into forestry problems. Originally a Union of Central European stations, it has steadily expanded until it now has members in all parts of the world; it is still attracting new recruits, and among recent accessions are the Academy of Sciences of the U.S.S.R. and the research stations of the Forest Service of the United States.

Most of the meetings of the Congress were held in the Imperial Forestry Institute; but the opening and closing ceremonies took place in Regent's Park College, Oxford. The Congress was formally opened by the Minister of Agriculture, Fisheries and Food, Mr. D. Heathcoat Amory, who spoke about forest policy in Great Britain and the place which research has taken in recent developments. He mentioned that much of the earlier effort was devoted to establishing crops of trees on land which had carried no tree growth for centuries; after about thirty years of effort, many of the problems of establishment have been solved, and British research workers are now turning their attention to the problems of managing forests. Work study and mechanization are being dealt with, and much interest is being taken in the effect of trees on the soil. Mr. Amory 